\title{
Degradabilidade ruminal da matéria seca de grãos de milho e de sorgo com alto ou baixo conteúdo de tanino processados ${ }^{1}$
}

\author{
Ruminal dry matter degradability of corn and sorghum grains at high or low tannin \\ contents submitted to processing
}

\author{
CAÇÃO, Márcia Marise de Freitas ${ }^{2}$; COSTA, Ciniro ${ }^{3}$; MEIRELLES, Paulo Roberto de \\ Lima $^{3 *}$, EZEQUIEL, Jane Maria Bertocco ${ }^{4}$; GALATI, Rosemary Lais ${ }^{5}$; SILVA, Marina \\ Gabriela Berchiol $^{6}$
}

\footnotetext{
${ }^{1}$ Parte da tese de doutorado da primeira autora.

${ }^{2}$ Agência Paulista de Tecnologias dos Agronegócios, Regional Médio Paranapanema, Assis, São Paulo, Brasil.

${ }^{3}$ Universidade Estadual Paulista, Faculdade de Medicina Veterinária e Zootecnia, Departamento de Melhoramento e Nutrição Animal, Botucatu, São Paulo, Brasil.

${ }^{4}$ Universidade Estadual Paulista, Faculdade Ciências Agrárias e Veterinária, Departamento de Zootecnia, Jaboticabal, São Paulo, Brasil.

${ }^{5}$ Universidade Federal de Mato Grosso, Faculdade de Agronomia, Medicina Veterinária e Zootecnia, Departamento de Zootecnia e Extensão Rural, Mato Grosso, Brasil.

${ }^{6}$ Universidade Estadual Paulista, Faculdade de Medicina Veterinária e Zootecnia, Programa de PósGraduação em Zootecnia, Botucatu,São Paulo, Brasil.

*Endereço para correspondência: paulom@fmvz.unesp.br
}

\section{RESUMO}

Avaliaram-se os efeitos da ensilagem, extrusão e secagem do milho e sorgo com alto e baixo conteúdo de tanino sobre a composição química e a degradação ruminal da matéria seca. $\mathrm{O}$ delineamento experimental foi inteiramente casualizado, em esquema fatorial $3 \times 3$, (tipos de grãos $\mathrm{x}$ processamentos) para a composição química e degradabilidade com três blocos (animais) pelo método in situ. Quanto à composição química, com exceção da proteína bruta e matéria mineral, constatou-se diferença significativa entre os tipos de grãos e processamentos. Os teores de extrato etéreo nos três tipos de grãos foram reduzidos significativamente com a ensilagem, extrusão e secagem em relação ao material úmido. Nos teores de fenóis, tanino total e condensado, houve efeito do híbrido, do processamento e da interação e, no sorgo com alto conteúdo de tanino, os teores mais elevados. Embora a composição dos grãos tenha sido similar, a interação no ambiente ruminal, associada ao tanino, proporcionou diferenças na degradabilidade da matéria seca. Concluiu-se que o sorgo com baixo conteúdo de tanino pode ser ensilado ou extrusado, enquanto o sorgo com alto conteúdo de tanino, deve ser extrusado, para melhorar a degradabilidade e a disponibilidade de nutrientes no rúmen.

Palavras chave: extrusão, fenóis totais, grãos secos, silagem de grão úmido

\section{SUMMARY}

This work evaluated the effects of high moisture silage, extrusion and corn and sorghum drying with and without tannin, on the chemical composition and ruminal digestion of dry matter. The experimental design was completely randomized in $3 \times 3$ factorial scheme (kinds of grains: processing), for the chemical composition and degradability and three blocks (animals) through in situ method. It was verified significant difference between kinds of grains and processing in relation to the chemical composition, except for crude protein and mineral matter. The contents of etherextract in the three types of grains, were reduced significantly with the high moisture silage, extrusion and drying in relation to the humid material. For the contents of phenols, total and 
condensed tannin there was effect of hybrid, processing and interaction, and the most elevated contents were found in sorghum with tannin. Although grain composition has been similar, the interaction in ruminal ambient associated to the tannin, promoted differences in the dry matter degradability. It was concluded that sorghum without tannin may be ensiled or extruded, while the sorghum with tannin, must be extruded to improve the degradability and availability of nutrients.

Keywords: dry grains, extrusion, high moisture silage of grain, total phenols

\section{INTRODUÇÃO}

O sucesso de uma exploração pecuária depende da utilização correta e eficiente das fontes de energia provenientes dos grãos de cereais, especialmente o milho e o sorgo. Atualmente, com o elevado custo de grãos, principalmente do milho, o sorgo pode ser uma alternativa para baratear o custo da ração e com a mesma eficiência daquele grão. Dependendo do processamento físico do grão, o sorgo pode apresentar 85 a $100 \%$ do valor nutricional do milho (IGARASI et al., 2008).

$\mathrm{O}$ uso de cereais úmidos objetiva reduzir as perdas quantitativas e qualitativas que ocorrem na lavoura e durante $o$ armazenamento, devido principalmente ao ataque de insetos, fungos, roedores e perda por tombamento (JOBIM et al., 2007). Esse tipo de utilização visa a, também, diminuir os custos de secagem e transporte. Além disso, no estádio úmido, a quantidade de nutrientes é maior e as condições para sua preservação mais adequadas, o que melhora a conversão alimentar dos ruminantes e monogástricos (LOPES et al., 2001ab; SARTORI et al., 2002; JOBIM et al., 2007).

Pesquisas mostraram que o sorgo deve ser processado mais intensamente que o milho (GAEBE et al.,1998; GOMIDE,1999; IGARASI et al., 2008).
O processamento dos grãos expõe os grânulos de amido à digestão (BEAUCHEMIN et al., 2001), o que facilita, por meio de fissuras, o ataque das enzimas e da população microbiana presente no processo digestivo, melhorando, com isso, a utilização do amido. Agentes mecânicos como moagem, trituração, laminação a seco, térmicos como o calor na extrusão e floculação e agentes químicos, como ácidos ou álcalis, podem induzir a gelatinização (porcentagem do conteúdo total do amido imediatamente acessível à glicoamilase) do amido, tornando-o mais digestível que o natural (VERVUERT et al., 2004). Nos grãos sem tratamento ou, tratados mecanicamente, o grau de gelatinização é normalmente zero. Entretanto, nos cereais processados por calor, espera-se que o amido seja gelatinizado (VERVUERT et al., 2004), o que aumenta a disponibilidade dos grânulos de amido e a eficiência do efeito das enzimas digestivas.

Nesse sentido, neste trabalho almejouse avaliar o efeito das formas de processamento (ensilagem, extrusão e secagem) de híbridos de milho e de sorgo (com alto e com baixo conteúdo de tanino) sobre a composição química, teores de fenóis, tanino total e condensado, bem como a degradação ruminal da matéria seca.

\section{MATERIAL E MÉTODOS}

O experimento foi realizado na Faculdade de Medicina Veterinária e Zootecnia da UNESP, Campus de Botucatu, a 800m de altitude. Foram testados grãos de milho e sorgo processados nas formas de silagem, extrusado e seco. Para a confecção das silagens, utilizou-se grãos de milho do cultivar Co 32 (híbrido triplo, semiprecoce, semiduro, alaranjado) e os 
híbridos de sorgo com baixo conteúdo de tanino (BT), o AG 1018, e com alto conteúdo de tanino (AT), o AG 3002, que foram colhidos com umidade média de $29 \%$, moídos em peneira média e armazenados em tambores plásticos de 200 litros com tampa, por seis meses. Os grãos secos de milho e de sorgo foram colhidos com 15 e $17 \%$ de umidade, respectivamente, e colocados para secar ao sol em terreiro de piso de concreto. O milho e o sorgo com alto conteúdo de tanino foram ensacados com $11 \%$ de umidade em sacos de polietileno, enquanto o sorgo com baixo conteúdo de tanino com $14 \%$ de umidade. Os grãos foram moídos em peneira (crivos de três $\mathrm{mm}$ ) para uso na forma seca e extrusada.

$\mathrm{O}$ delineamento experimental utilizado para verificar os efeitos dos diferentes tipos de grãos e os diferentes tipos de processamentos foi $o$ inteiramente casualizado, com arranjo fatorial $3 \times 3$, sendo três tipos de grãos (milho e sorgos com baixo e com alto conteúdo de tanino) e três processamentos (seco, ensilado e extrusado), para a avaliação da composição químico-bromatológica e do teor de tanino. Para a avaliação da degradabilidade ruminal foi utilizado delineamento em blocos casualizados, em parcelas subdivididas e esquema fatorial $3 \times 3$, sendo três tipos de grãos (milho, sorgo com baixo e com alto conteúdo de tanino), três formas de processamentos (moído seco, ensilagem e extrusão), três blocos (animais) e cinco tempos de permanência no rúmen ( $2 ; 4 ; 6 ; 12 ; 24$ e 48 horas).

Os teores de matéria seca (MS), proteína bruta $(\mathrm{PB})$, extrato etéreo (EE), matéria mineral (MM) e fibra bruta (FB) dos sorgos e milho, secos, ensilados e extrusados, foram determinados conforme as metodologias descritas na AOAC (2002). Todas as amostras úmidas foram submetidas à pré-secagem em estufa de circulação e renovação de ar, a temperatura de $35^{\circ} \mathrm{C}$ por um período de 72 horas, para que não houvesse interferência na determinação do teor de tanino. Os teores de fenóis totais, tanino total e tanino condensado foram determinados a partir da metodologia descrita por Makkar et al. (1993).

Para o ensaio de degradabilidade ruminal in situ foram utilizados três bovinos machos, castrados, mestiços Holandês $\mathrm{x}$ Zebu, que pesavam aproximadamente $700 \mathrm{~kg}$ e providos de cânulas permanentes no rúmen. Antes de iniciar a fase experimental, os animais foram submetidos ao controle de endo e ectoparasitos. Os animais permaneceram durante a fase experimental em baias individuais, que mediam $1,10 \times 2,20 \mathrm{x}$ $1,65 \mathrm{~m}$, e recebiam dieta composta de volumoso e concentrado na relação 40:60 na matéria seca. $\mathrm{O}$ volumoso utilizado foi o capim-elefante picado fresco (com média de $30 \%$ de $\mathrm{MS}$ ), enquanto o concentrado está descrito na Tabela 1. A dieta foi fornecida duas vezes ao dia, às sete $\mathrm{e}$ às 17 horas, na quantidade equivalente a $1,6 \% \mathrm{PV}$ em MS.

$\mathrm{O}$ período experimental teve duração total de 100 dias, divididos em quatro períodos de 25 dias, dos quais 15 dias destinados à adaptação às dietas e 10 dias à coleta de material. Foi utilizada a técnica de degradação ruminal in situ (ORSKOV \& MCDONALD, 1979), utilizando-se sacos de tecido em poliéster, medindo $14,0 \mathrm{~cm} \times 7,0 \mathrm{~cm}$, com poros de 50 micrômetros. Para as incubações ruminais os grãos de milho e sorgo, nas três formas de processamento: moído seco, ensilado e extrusado, foram moídos utilizando-se peneiras com crivos de $2 \mathrm{~mm}$ de diâmetro.

Os tempos de permanência no rúmen foram: $2 ; 4 ; 6 ; 12 ; 24$ e 48 horas. Os sacos correspondentes a cada horário foram inseridos no rúmen, sempre $\mathrm{e}$ imediatamente após a refeição da 
manhã, de forma que o horário seguinte somente era inserido depois de decorrido todo o período do primeiro. Os sacos de náilon foram lavados em água fria corrente para retirar o excesso de conteúdo ruminal e em seguida mergulhado por 30 minutos em balde com água gelada para interrupção da atividade microbiana. Logo após, foram lavados em máquina tanquinho durante 15 minutos com renovação de água até que a mesma ficasse completamente limpa (TEIXEIRA et al., 1989). A fração solúvel foi determinada em água, ao se lavar os sacos com as amostras separadamente de qualquer horário, respeitando-se o tempo e $\mathrm{o}$ número de batidas de cada lavagem.

Tabela 1. Composição percentual dos concentrados utilizados nas dietas dos animais no experimento de degradabilidade ruminal in situ (\% na matéria seca)

\begin{tabular}{lcc}
\hline Alimento & $\begin{array}{c}\text { Sorgo com baixo conteúdo de } \\
\text { tanino (BT) }\end{array}$ & $\begin{array}{c}\text { Sorgo com alto conteúdo de } \\
\text { tanino (AT) }\end{array}$ \\
\hline Milho ensilado & 14,5 & 14,5 \\
Milho extrusado & 11,7 & 11,7 \\
Milho seco & 12,0 & 12,0 \\
Sorgo ST ensilado & 14,5 & - \\
Sorgo ST extrusado & 11,9 & - \\
Sorgo ST seco & 11,9 & - \\
Sorgo CT ensilado & - & 14,5 \\
Sorgo CT extrusado & - & 11,9 \\
Sorgo CT seco & - & 11,9 \\
Farelo de soja & 23,5 & 23,5 \\
\hline
\end{tabular}

Após essa etapa, os sacos que continham os resíduos da incubação foram colocados em estufa de circulação e renovação de ar a temperatura de $35^{\circ} \mathrm{C}$ por um período de 72 horas. Os resíduos não digeridos e insolúveis foram pesados após estarem secos e em equilíbrio com a temperatura ambiente.

Para avaliação da degradação potencial da matéria seca foi utilizado o modelo proposto por Orskov \& Mcdonald (1979):

$\mathrm{p}=\mathrm{a}+\mathrm{b}\left(1-\mathrm{e}^{\mathrm{kt}}\right)$

em que:

$\mathrm{p}=$ degradação potencial do componente nutritivo, em porcentagem; $\mathrm{a}=$ fração solúvel, em porcentagem;

$\mathrm{b}=$ fração insolúvel potencialmente degradável, em porcentagem;

$\mathrm{a}+\mathrm{b}=$ potencial de digestão do componente nutritivo;

$\mathrm{kd}=$ taxa de digestão por ação fermentativa, em porcentagem por hora; $t=$ tempo de incubação, em horas.

Para determinação da degradabilidade efetiva foi utilizada a expressão:

$\mathrm{P}=\mathrm{a}+\mathrm{b} \mathrm{kd}\left(\mathrm{kd}+\mathrm{k}_{\mathrm{p}}\right)^{-1}$

em que:

$\mathrm{P}=$ degradabilidade efetiva, em porcentagem;

$\mathrm{k}_{\mathrm{p}}=$ taxa de passagem das frações nutritivas por hora,

Foram utilizadas as taxas de 2,5 e $8 \% / \mathrm{h}$ (AFRC, 1993).

Os resultados foram analisados por meio do programa Statistical Analysis System (SAS, 2001) e as médias foram comparadas pelo teste de Tukey a $5 \%$ de probabilidade. 
Rev. Bras. Saúde Prod. Anim., Salvador, v.13, n.2, p.516-528 abr./jun., 2012 http://www.rbspa.ufba.br ISSN 15199940

\section{RESULTADOS E DISCUSSÃO}

Para os nutrientes avaliados com exceção da $\mathrm{PB}$ e da MM, constatou-se diferença para os três tipos de grãos e processamentos (Tabela 2). Os valores encontrados para os teores de $\mathrm{PB}$ oscilaram entre 8,7 e $10,7 \%$ para o milho e entre 9,9 e $11,1 \%$ para o sorgo, o que confirma os dados encontrados na literatura para esses grãos (GAEBE et al.,1998, GOMIDE,1999 e IGARASI et al., 2008). Vale ressaltar, que o sorgo pode apresentar nível de proteína bruta um pouco superior ao do milho, além de alta variabilidade da PB.

Tabela 2. Composição química em proteína bruta $(\mathrm{PB})$, extrato etéreo (EE), matéria mineral (MM) e fibra bruta (FB) do milho e do sorgo com alto (AT) e baixo (BT) conteúdo de tanino (\%), com base na matéria seca (MS)

\begin{tabular}{|c|c|c|c|c|c|}
\hline \multicolumn{2}{|c|}{ Fonte de MS } & \multicolumn{4}{|c|}{$\% \mathrm{MS}$} \\
\hline & & $\mathrm{PB}^{\mathrm{NS}}$ & $\mathrm{EE}$ & $\mathrm{MM}^{\mathrm{NS}}$ & FB \\
\hline & \multicolumn{5}{|c|}{ Milho } \\
\hline Ensilado & $72,0^{b}$ & 8,7 & $4,9^{b}$ & 1,0 & 1,8 \\
\hline Extrusado & $89,6^{\mathrm{a}}$ & 9,6 & $2,1^{\mathrm{c}}$ & 1,3 & 2,3 \\
\hline Seco & $87,6^{\mathrm{a}}$ & 10,7 & $5,0^{\mathrm{b}}$ & 1,4 & 2,4 \\
\hline \multirow[t]{2}{*}{ Úmido } & $71,6^{\mathrm{b}}$ & 8,8 & $6,8^{\mathrm{a}}$ & 1,2 & 2,6 \\
\hline & \multicolumn{5}{|c|}{ Sorgo BT } \\
\hline Ensilado & $64,7^{b}$ & 9,9 & $5,4^{b}$ & 1,3 & $1,8^{\mathrm{b}}$ \\
\hline Extrusado & $87,8^{\mathrm{a}}$ & 10,9 & $1,6^{\mathrm{d}}$ & 1,1 & $1,9^{\mathrm{ab}}$ \\
\hline Seco & $86,8^{\mathrm{a}}$ & 11,1 & $3,4^{\mathrm{c}}$ & 1,2 & $2,4^{\mathrm{a}}$ \\
\hline \multirow[t]{2}{*}{ Úmido } & $64,3^{\mathrm{a}}$ & 10,2 & $6,3^{\mathrm{a}}$ & 1,7 & $2,2^{\mathrm{a}}$ \\
\hline & \multicolumn{5}{|c|}{ Sorgo AT } \\
\hline Ensilado & $62,4^{b}$ & 10,1 & $4,1^{b}$ & 1,2 & 2,2 \\
\hline Extrusado & $88,1^{\mathrm{a}}$ & 11,2 & $1,3^{\mathrm{d}}$ & 1,3 & 2,1 \\
\hline Seco & $87,4^{\mathrm{a}}$ & 11,0 & $3,1^{\mathrm{c}}$ & 1,0 & 2,5 \\
\hline Úmido & $62,4^{\mathrm{b}}$ & 10,1 & $5,5^{\mathrm{a}}$ & 1,2 & 2,5 \\
\hline CV (\%) & 1,0 & 6,0 & 19,5 & 28,0 & 8,6 \\
\hline
\end{tabular}

Médias seguidas de letras distintas minúsculas nas colunas diferem estatisticamente entre si $(\mathrm{P}<0,05)$, pelo teste de Tukey.

Hibberd et al. (1982) encontraram diferenças no teor de proteína, com valores entre 11,0 e $16,5 \%$ de acordo com a variedade de sorgo e o ano de cultivo e mostraram que as condições ambientais durante a estação de crescimento afetaram a composição química e a disponibilidade de nutrientes na semente. Nesse contexto, o sorgo, pode ser considerado equivalente ao milho em minerais, vitaminas e pobre em substâncias pigmentantes. Além disso, pode conter, conforme a variedade, compostos fenólicos como o tanino (BARCELOS et al., 2006).

Conforme se esperava, houve diferença $(\mathrm{P}<0,05)$ entre os grãos e processamentos quanto ao teor de MS (Tabela 2). Os valores obtidos para o milho e sorgo secos foram próximos ao teor recomendado de $87 \%$ de MS para adequada conservação e preservação de grãos (JOBIM et al. 2007), enquanto que 
para ensilagem de grãos úmidos apenas o teor de MS do milho mostrou-se dentro do intervalo de 68 a $74 \%$ de MS, recomendado por Jobim et al. (2007). Nessa direção, Lee et al. (2002), ao trabalharem com digestibilidade in vitro da MS do milho, reportaram valores de 90,$31 ; 76,48$ e $61,68 \%$ em relação aos processamentos de moagem fina (1mm), quebra (4mm) e floculação, respectivamente.

No que concerne aos teores de EE, verifica-se que o processamento, alterou os valores $(\mathrm{P}<0,05)$ desse componente entre os tipos de grãos. A partir da maturação fisiológica, constatou-se redução significativa com a secagem, a ensilagem e a extrusão. A principal redução ocorreu com o processo de extrusão, durante o qual provavelmente houve a oxidação dos lipídios ou a formação de complexos com amido, o que dificulta a sua extração com solvente orgânico. O calor da extrusão e da floculação favorece a gelatinização do amido tornando-o mais digestível que o natural, entretanto esse processo pode promover complexação com lipídios (VERVUERT et al., 2004).

Os teores de fenóis totais (FT), tanino total (TT) e tanino condensado (TC), em sorgo com alto conteúdo de tanino (AT) e baixo conteúdo de tanino (BT) estão na Tabela 3. Houve efeito $(\mathrm{P}<0,05)$ de tipo de grão, de processamento e da interação entre eles. A quantidade de taninos sintetizados pela planta depende da espécie, cultivar, tecido, estágio de desenvolvimento e condições ambientais. Esses fatores influenciam na concentração, e nas características que podem determinar a ação desses fenóis na qualidade nutricional das plantas (McSWEENEY et al., 2001).

Tabela 3. Médias de fenóis totais (FT), tanino total (TT) e tanino condensado (TC), em sorgo com alto conteúdo de tanino (AT) e baixo conteúdo de tanino (BT)

\begin{tabular}{llcccc}
\hline Fonte de variação & Ingrediente & Ensilado & Extrusado & Seco & Úmido \\
\hline \multirow{2}{*}{ FT $^{*}$} & Sorgo BT & $0,47^{\mathrm{Ab}}$ & $0,57^{\mathrm{Ab}}$ & $0,35^{\mathrm{Ab}}$ & $0,18^{\mathrm{Bb}}$ \\
& Sorgo AT & $1,46^{\mathrm{Aa}}$ & $1,20^{\mathrm{Aa}}$ & $0,92^{\mathrm{Ba}}$ & $1,40^{\mathrm{Aa}}$ \\
\hline \multirow{2}{*}{$\mathrm{TT}^{*}$} & Sorgo BT & $0,31^{\mathrm{Ab}}$ & $0,33^{\mathrm{Ab}}$ & $0,25^{\mathrm{Ab}}$ & $0,11^{\mathrm{Ab}}$ \\
& Sorgo AT & $1,46^{\mathrm{Aa}}$ & $1,13^{\mathrm{Ba}}$ & $0,75^{\mathrm{Ca}}$ & $1,20^{\mathrm{Ba}}$ \\
\hline \multirow{2}{*}{ TC $^{* *}$} & Sorgo BT & 0,00 & 0,00 & 0,00 & 0,00 \\
& Sorgo AT & $2,25^{\mathrm{Aa}}$ & $1,63^{\mathrm{Ba}}$ & $1,03^{\mathrm{Ca}}$ & $2,03^{\mathrm{Aa}}$ \\
\hline
\end{tabular}

Médias seguidas de letras distintas minúsculas nas colunas e maiúsculas nas linhas diferem estatisticamente entre si $(\mathrm{P}<0,05)$.

*Valores expressos em \% da matéria seca, como equivalente-grama de ácido tânico.

**Valores expressos em \% de MS, como equivalente-grama de leucocianidina.

A partir da maturação fisiológica, houve aumento nos teores de fenóis e tanino total para o sorgo com baixo conteúdo de tanino, enquanto que para o sorgo com alto conteúdo de tanino os valores tenderam a se estabilizar ou tiveram pequena redução. A ensilagem e a extrusão não afetaram $(\mathrm{P}>0,05)$ o teor de fenóis no sorgo com alto conteúdo de tanino, respectivamente $1,46 \mathrm{e}$ $1,20 \%$, em relação ao material úmido natural de $1,40 \%$, mas no grão seco o teor diminuiu para $0,92 \%$. No sorgo com baixo conteúdo de tanino, não houve diferença $(\mathrm{P}>0,05)$ entre grãos secos $(0,35)$, ensilados $(0,47)$ e 
extrusados $(0,57)$, porém estes foram superiores $(\mathrm{P}<0,05)$ aos grãos úmidos $(0,18)$.

Para o teor de tanino total não houve efeito $(\mathrm{P}>0,05)$ do processamento no sorgo com baixo conteúdo de tanino, mas no sorgo com alto conteúdo de tanino a ensilagem provocou aumento $(1,46 \%)$, a extrusão manteve $(1,13 \%)$ e a secagem reduziu o teor $(0,75 \%)$ em relação ao material úmido $(1,20 \%)$. Possivelmente, nessa pesquisa, a extrusão, em virtude da ação do calor e da pressão, provocou a quebra de outras moléculas na forma de $\mathrm{OH}$ como a hemicelulose, o que produziu outros compostos fenólicos, que não o tanino. Barcelos et al. (2006) encontraram para as silagens de grãos úmidos de sorgo com alto e baixo conteúdo de tanino 3.434 e $3.505 \mathrm{kcal} / \mathrm{kg}$ de ED e 3.400 e $3.461 \mathrm{kcal} / \mathrm{kg}$ de EM, respectivamente. Resultados semelhantes foram obtidos por Oliveira et al. (2004) que utilizaram silagem de grãos úmidos de milho.

Para Patricio et al. (2006), os teores de tanino no sorgo de baixo conteúdo de tanino variaram de 0,44 a $0,69 \%$, percentuais abaixo de $0,70 \%$ de polifenóis totais são decorrentes de outros fenóis e não prejudicam o desempenho animal.

Não foi detectada presença de tanino condensado no sorgo com baixo conteúdo de tanino. Por outro lado, no sorgo com alto conteúdo de tanino, o processamento alterou $(\mathrm{P}<0,05)$ a concentração desse composto nos grãos, enquanto que a secagem e a extrusão reduziram seu teor e a ensilagem aumentou.

Magalhães et al. (1997) afirmam que a determinação da presença dos taninos no grão de sorgo apresenta vários problemas, uma vez que os métodos utilizados geralmente não diferenciam taninos de outros compostos fenólicos, além da capacidade dos taninos de se complexarem com diversos compostos.
Outra dificuldade é a obtenção de substâncias adequadas para serem utilizadas como padrão para estes métodos.

Price et al. (1979) verificaram que a concentração de tanino decresceu com a secagem do grão de sorgo imaturo, após fervura por três minutos ou congelamento, seguido da secagem em temperatura de 22 a $105^{\circ} \mathrm{C}$. Esses autores observaram que o teor de tanino pode aumentar, permanecer constante, aumentar gradualmente e então estacionar ou decrescer, dependendo da variedade ou quando o grão amadurece. $\mathrm{O}$ teor de tanino pode também variar conforme a metodologia utilizada na análise, armazenamento. Nesse sentido, a adoção de estratégias que possibilitem atenuar o efeito do tanino sobre o metabolismo animal ou a utilização desses compostos em concentrações que permitam o efeito benéfico parecem ser estratégias adequadas (ODENYO et al., 2001).

A interação dos tipos de grãos estudados e processamentos com os desdobramentos para a fração solúvel "a", insolúvel potencialmente degradável "b", indegradável "c", taxa de fermentação em \%/h " $k d$ ", são apresentados na Tabela 4, enquanto as degradabilidades potencial e efetiva para as taxas de passagem de $2 ; 5$ e $8 \% /$ hora, para MS, estão na Tabela 5 .

No que diz respeito à fração "a", não houve interação $(\mathrm{P}>0,05)$ entre os tipos de grãos e processamento. Os resultados encontrados para essa fração nos ensilados de milho (88,6\%), no sorgo com baixo conteúdo de tanino $(58,8 \%)$ e no sorgo com alto conteúdo de tanino $(33,3 \%)$ foram superiores aos encontrados por Passini et al. (2002), que foram de $50,8 \%$ e $15,9 \%$, para milho e sorgo, respectivamente.

Segundo Tonani et al. (2001), o desaparecimento da fração "a" caracteriza a solubilização dos açúcares e compostos 
nitrogenados solúveis remanescentes da fermentação no silo, constituída, principalmente, de sacarose, frutose, glicose e pequenas quantidades de manose e galactose. De acordo com Van Soest et al. (1994), o processamento por extrusão aumenta os valores da fração "a" dos alimentos, disponibilizando maior quantidade de carboidratos prontamente solúveis no rúmen, onde são rapidamente digeridos quase na sua totalidade.

Bertipaglia et al. (2008), ao avaliar o efeito da extrusão em grãos de soja e milho, verificou que o processamento aumentou os valores da fração "a" em aproximadamente $60 \%$. Enquanto, no presente estudo, a extrusão elevou a solubilidade da fração "a", em 53,8\%.

A fração solúvel nos grãos secos foi muito baixa principalmente para $\mathrm{o}$ milho (20,7\%), mas semelhante ao valor encontrado por Goes et al. (2004) e inferior aos valores comumente observados (MARCONDES et al., 2009; PASSINI et al., 2004; OLIVEIRA et al., 2003; VALADARES FILHO et al.,2006). A não ocorrência de interação para a fração solúvel, pode ser atribuída ao uso de sacos de náilon para fazer degradação da MS. Nesse sentido, Casali et al., (2009) mostraram que esse material tem alta porosidade, o que acarreta maiores erros de estimação da fração " $a$ ".

Tabela 4. Frações solúvel (a), insolúvel potencialmente degradável (b), e indegradável (c), taxa de fermentação (kd) da matéria seca do milho, sorgo com baixo (BT) e com alto conteúdo de tanino (AT), ensilados, extrusados e secos

\begin{tabular}{llrcc}
\hline \multirow{2}{*}{ Variáveis } & \multirow{2}{*}{ Processamento } & \multicolumn{3}{c}{ Grãos } \\
\cline { 3 - 5 } & & Milho & Sorgo BT & Sorgo AT \\
\hline \multirow{3}{*}{$\mathrm{a}^{*}$} & Ensilagem & $88,6^{\mathrm{a}}$ & $58,8^{\mathrm{a}}$ & $33,3^{\mathrm{a}}$ \\
& Extrusão & $38,5^{\mathrm{a}}$ & $45,4^{\mathrm{a}}$ & $44,5^{\mathrm{a}}$ \\
& Seco & $20,7^{\mathrm{a}}$ & $26,1^{\mathrm{a}}$ & $27,9^{\mathrm{a}}$ \\
\hline \multirow{3}{*}{$\mathrm{b}$} & Ensilagem & $4,8^{\mathrm{Bc}}$ & $34,8^{\mathrm{Ab}}$ & $29,8^{\mathrm{Ab}}$ \\
& Extrusão & $53,1^{\mathrm{Ab}}$ & $45,7^{\mathrm{Aa}}$ & $34,6^{\mathrm{Bb}}$ \\
& Seco & $68,5^{\mathrm{Aa}}$ & $44,3^{\mathrm{Aa}}$ & $42,2^{\mathrm{Aa}}$ \\
\hline \multirow{2}{*}{$\mathrm{c}$} & Ensilagem & $6,5^{\mathrm{Bb}}$ & $6,4^{\mathrm{Bb}}$ & $36,9^{\mathrm{Aa}}$ \\
& Extrusão & $8,4^{\mathrm{Bb}}$ & $8,9^{\mathrm{Bb}}$ & $20,9^{\mathrm{Ab}}$ \\
& Seco & $10,8^{\mathrm{Ba}}$ & $29,5^{\mathrm{Aa}}$ & $29,9^{\mathrm{Aa}}$ \\
\hline \multirow{2}{*}{$\mathrm{Kd}$} & Ensilagem & $3,0^{\mathrm{Aa}}$ & $3,6^{\mathrm{Aa}}$ & $2,7^{\mathrm{Aa}}$ \\
& Extrusão & $5,2^{\mathrm{Aa}}$ & $3,7^{\mathrm{Aa}}$ & $4,6^{\mathrm{Aa}}$ \\
& Seco & $4,0^{\mathrm{Aa}}$ & $1,2^{\mathrm{Ba}}$ & $2,7^{\mathrm{Aa}}$ \\
\hline
\end{tabular}

Médias seguidas de letras distintas minúsculas nas colunas e maiúsculas nas linhas diferem estatisticamente entre si $(\mathrm{P}<0,05)$, pelo teste de Tukey.

${ }^{a *}$ Não houve interação tipo de grãos x processamentos.

O milho ensilado foi superior $(\mathrm{P}<0,05)$ ao sorgo com baixo conteúdo de tanino e ao sorgo com alto conteúdo de tanino na fração insolúvel, potencialmente degradável "b" e degradabilidades efetivas (DE) da MS para todas as taxas de passagem. Embora as composições do milho e dos dois híbridos de sorgo tenham sido similares, a interação desses ingredientes, no ambiente ruminal, associada à presença do tanino, proporcionou diferenças na cinética 
Rev. Bras. Saúde Prod. Anim., Salvador, v.13, n.2, p.516-528 abr./jun., 2012 http://www.rbspa.ufba.br ISSN 15199940

da digestão, indicando que ao substituir o milho por sorgo, essas diferenças precisam ser consideradas. O processo de ensilagem aumentou a solubilidade da MS do milho ensilado em detrimento da fração " $b$ ". Isso sugere que na ensilagem, nutrientes como a proteína e o amido sejam disponibilizados mais facilmente ao ataque microbiano.

Com a extrusão, a fração insolúvel potencialmente degradável da MS do milho foi diferente do sorgo com baixo conteúdo de tanino. No processo de extrusão, o sorgo com alto conteúdo de tanino apresentou a maior fração "c" $(20,9 \%)$, enquanto o milho e sorgo de baixo conteúdo de tanino, por sua vez, foram semelhantes. A taxa de fermentação $(\mathrm{kd})$, não foi influenciada pelo processamento para nenhum dos tipos de grãos (Tabela 4).

Houve efeito $(\mathrm{P}<0,05)$ do processamento para os grãos de milho e sorgo BT em relação degradabilidade potencial, $\mathrm{O}$ que mostra que o processamento dos grãos melhorou a degradabilidade por disponibilizar favoravelmente os nutrientes (Tabela 5). Para o sorgo AT, a extrusão melhorou a degradabilidade, já os ensilados e secos não diferiram $(\mathrm{P}>0,05)$. O processo de ensilagem não foi suficiente para alterar a concentração de tanino, nem influenciar a degradabilidade.

Tabela 5. Degradabilidade potencial e efetiva (em \%) para as taxas de passagem de 2 , 5 e $8 \% / h$, da matéria seca do milho, sorgo BT e sorgo AT, ensilados, extrusados e secos

\begin{tabular}{|c|c|c|c|c|}
\hline \multirow{2}{*}{ Variáveis } & \multirow{2}{*}{ Processamento } & \multicolumn{3}{|c|}{ Ingredientes } \\
\hline & & Milho & Sorgo BT & Sorgo AT \\
\hline \multirow{3}{*}{ Deg. Potencial } & Ensilagem & $91,5^{\mathrm{Aa}}$ & $86,0^{\mathrm{Aa}}$ & $53,1^{\mathrm{Bb}}$ \\
\hline & Extrusão & $85,8^{\mathrm{Aa}}$ & $82,6^{\mathrm{Aa}}$ & $72,8^{\mathrm{Ba}}$ \\
\hline & Seco & $78,3^{\mathrm{Ab}}$ & $45,8^{\mathrm{Bb}}$ & $57,9^{\mathrm{Ab}}$ \\
\hline CV (\%) & \multicolumn{4}{|c|}{6,2} \\
\hline \multirow{3}{*}{ Deg. Efetiva $2 \% / h$} & Ensilagem & $91,0^{\mathrm{Aa}}$ & $80,3^{\mathrm{Aa}}$ & $49,2^{\mathrm{Bb}}$ \\
\hline & Extrusão & $76,0^{\mathrm{Ab}}$ & $74,6^{\mathrm{Aa}}$ & $67,1^{\mathrm{Ba}}$ \\
\hline & Seco & $66,0^{\mathrm{Ac}}$ & $42,9^{\mathrm{Ba}}$ & $51,8^{\mathrm{Ab}}$ \\
\hline CV (\%) & \multicolumn{4}{|c|}{5,4} \\
\hline \multirow{3}{*}{ Deg. Efetiva $5 \% / h$} & Ensilagem & $90,1^{\mathrm{Aa}}$ & $72,8^{\mathrm{Aa}}$ & $43,0^{\mathrm{Bb}}$ \\
\hline & Extrusão & $64,8^{\mathrm{Ab}}$ & $64,4^{\mathrm{Ab}}$ & $59,8^{\mathrm{Ba}}$ \\
\hline & Seco & $50,9^{\mathrm{Ac}}$ & $34,9^{\mathrm{Bb}}$ & $42,5^{\mathrm{Bb}}$ \\
\hline CV (\%) & \multicolumn{4}{|c|}{5,7} \\
\hline \multirow{3}{*}{ Deg. Efetiva $8 \% / h$} & Ensilagem & $89,7^{\mathrm{Aa}}$ & $69,2^{\mathrm{Aa}}$ & $40,3^{\mathrm{Bb}}$ \\
\hline & Extrusão & $58,9^{\mathrm{Ab}}$ & $59,5^{\mathrm{Ab}}$ & $56,2^{\mathrm{Ba}}$ \\
\hline & Seco & $43,4^{\mathrm{Ac}}$ & $32,0^{\mathrm{Bb}}$ & $38,4^{\mathrm{Bb}}$ \\
\hline CV (\%) & \multicolumn{4}{|c|}{5,4} \\
\hline
\end{tabular}

Médias seguidas de letras distintas minúsculas nas colunas e maiúsculas nas linhas diferem estatisticamente entre si $(\mathrm{P}<0,05)$, pelo teste de Tukey. 
No que diz respeito à degradabilidade efetiva, verifica-se que a ensilagem foi o processamento que produziu melhores resultados. O sorgo AT foi o grão que apresentou as menores degradabilidades, provavelmente, devido ao efeito do tanino sobre os microrganismos ruminais.

Gaebe et al. (1998) não encontraram diferenças entre milho e sorgo laminados ou extrusados nos parâmetros da digestão da MS, bem como no desaparecimento da matéria MS. Mendes et al. (2006) observaram que o tempo de retenção retículo-rúmen do grão de milho moído a $2 \mathrm{~mm}$ foi de 15 horas. Nesse sentido, ao considerar que o tempo de retenção máximo seria de 15 horas, e ao analisar o desaparecimento da MS 12 horas após a incubação ruminal (Tabela 6), observa-se que a ensilagem não contribuiu para o aumento no desaparecimento do sorgo com alto conteúdo de tanino. Entretanto, a extrusão foi o processamento mais importante para este híbrido. Cabe salientar que, moagem dos grãos aumenta a superfície para ação das enzimas digestivas, o que melhora a digestibilidade dos nutrientes (SILVA et al., 2005).

Tabela 6. Desaparecimento da matéria seca do milho, do sorgo com baixo (BT) e com alto conteúdo de tanino (AT)

\begin{tabular}{llcccccc}
\hline Item & Horário & 2 & 4 & 6 & 12 & 24 & 48 \\
\hline \multirow{2}{*}{ Ensilado } & Milho & $86,3^{\mathrm{Ba}}$ & $87,9^{\mathrm{Aa}}$ & $88,9^{\mathrm{Aa}}$ & $89,0^{\mathrm{Aa}}$ & $89,9^{\mathrm{Aa}}$ & $93,5^{\mathrm{Aa}}$ \\
& Sorgo BT & $63,3^{\mathrm{Bb}}$ & $66,2^{\mathrm{Bb}}$ & $70,3^{\mathrm{Bb}}$ & $75,8^{\mathrm{Bb}}$ & $79,6^{\mathrm{Bb}}$ & $93,6^{\mathrm{Aa}}$ \\
& Sorgo AT & $31,7^{\mathrm{Bc}}$ & $29,8^{\mathrm{Bc}}$ & $31,4^{\mathrm{Bc}}$ & $35,6^{\mathrm{Bc}}$ & $43,9^{\mathrm{Bc}}$ & $63,0^{\mathrm{Ab}}$ \\
\hline \multirow{2}{*}{ Extrusado } & Milho & $66,8^{\mathrm{Ca}}$ & $69,4^{\mathrm{Ca}}$ & $72,9^{\mathrm{Ca}}$ & $76,2^{\mathrm{Ca}}$ & $83,5^{\mathrm{Ba}}$ & $91,6^{\mathrm{Aa}}$ \\
& Sorgo BT & $62,3^{\mathrm{Ba}}$ & $67,4^{\mathrm{Ba}}$ & $68,5^{\mathrm{Ba}}$ & $72,6^{\mathrm{Ba}}$ & $78,9^{\mathrm{Ba}}$ & $91,1^{\mathrm{Aa}}$ \\
& Sorgo AT & $50,8^{\mathrm{Bb}}$ & $52,7^{\mathrm{Bb}}$ & $58,9^{\mathrm{Bb}}$ & $60,2^{\mathrm{Bb}}$ & $67,6^{\mathrm{Bb}}$ & $79,1^{\mathrm{Ab}}$ \\
\hline \multirow{2}{*}{ Seco } & Milho & $26,7^{\mathrm{Da}}$ & $29,5^{\mathrm{Da}}$ & $32,8^{\mathrm{Da}}$ & $45,4^{\mathrm{Ca}}$ & $62,4^{\mathrm{Ba}}$ & $89,2^{\mathrm{Aa}}$ \\
& Sorgo BT & $27,0^{\mathrm{Ca}}$ & $30,9^{\mathrm{Ca}}$ & $28,0^{\mathrm{Ca}}$ & $31,9^{\mathrm{Cb}}$ & $40,9^{\mathrm{Bb}}$ & $70,5^{\mathrm{Ab}}$ \\
& Sorgo AT & $27,8^{\mathrm{Ca}}$ & $27,9^{\mathrm{Ca}}$ & $29,9^{\mathrm{Ca}}$ & $33,2^{\mathrm{Cb}}$ & $46,2^{\mathrm{Bb}}$ & $70,1^{\mathrm{Ab}}$ \\
\hline
\end{tabular}

Médias seguidas de letras distintas minúsculas nas colunas e maiúsculas nas linhas diferem estatisticamente entre si $(\mathrm{p}<0,05)$, pelo teste de Tukey.

Os processamentos, principalmente a extrusão, proporcionaram forte redução nos teores de extrato etéreo do milho e do sorgo com baixo e com alto conteúdo de tanino. $\mathrm{O}$ milho e o sorgo com baixo conteúdo de tanino devem ser ensilados ou extrusados, enquanto que o sorgo com alto conteúdo de tanino deve ser extrusado para melhorar a degradabilidade e a disponibilidade dos nutrientes no rúmen.

\section{REFERÊNCIAS}

AGRICULTURAL AND FOOD

RESEARCH COUNCIL - AFRC..

Energy and protein requirements of

ruminants. Tecnical Committee on

Responses to Nutrients. Wallingford:

CAB International, 1993. 
Rev. Bras. Saúde Prod. Anim., Salvador, v.13, n.2, p.516-528 abr./jun., 2012 http://www.rbspa.ufba.br ISSN 15199940

ASSOCIATION OF OFFICIAL ANALYTICAL CHEMISTS - AOAC. Official methods of analysis. 17.ed. Washington: A.O.A.C., 2002.

BARCELLOS, L.C.G.; FURLAN, A.C.; MURAKAMI, A.E.; SILVA, M.A.A, SILVA, R.M. Avaliação nutricional da silagem de grãos úmidos de sorgo de alto ou de baixo conteúdo de tanino para frangos de corte. Revista Brasileira de Zootecnia, v.35, n.1, p.104-112, 2006.

BEAUACHEMIN, K.A.; YANG, W.Z.; RODE, L.M. Effects of barley grain processing on the site and extent of digestion of beef feedlot finishing diets.

Journal of Animal Science, v.79, p.1925-1934, 2001.

BERTIPAGLIA, L.M.A.; MELO, G.M.P.; SUGOHARA, A.; MELO, W.J.; BERTIPAGLIA, L.A. Alterações bromatológicas em soja e milho processados por extrusão (Chemical changes in soybean and corn processed by extrusion). Revista Brasileira de Zootecnia, v.37, n.11, p.2003-2010, 2008 .

CASALI, A.O.; DETMANN, E.; VALADARES FILHO, S.C.; PEREIRA,J.C.; CUNHA, M.; DETMANN, K.S.C.; PAULINO, M.F. Estimação de teores de Componentes fibrosos em alimentos para ruminantes em sacos de diferentes tecidos. Revista Brasileira de Zootecnia, v.38, n.1, p.130-138, 2009.

GAEBE, R.J.; SANSON, D.W.; RUSH, L.G.; RILEY, M.L.; HIXON, D.L.; PAISLEY, S.I. Effects of extruded corn or grain sorghum on intake, digestibility, weight gain, and carcasses of finishing steers. Journal of Animal Science, v.76, p.2001-2007, 1998.
GOES, R.H.T.B.; MANCIO, A.B.; VALADARES FILHO, S.C.; LANA, R.P. Degradação ruminal da matéria seca e da proteína bruta, de alimentos concentrados utilizados como suplementos para novilhos. Ciência Agrotécnica, v.28, n.1, p.167-173, 2004.

GOMIDE, I.F. Cinética da digestão ruminal do amido, amilose e amilopectina de diferentes grãos em misturas com uréia. 1999. 56 p. Dissertação (Mestrado em Zootecnia) - Universidade Federal de Lavras, Lavras.

HIBBERD, C.A.; WAGNER, D.G.; SCHEMM, R.L. MITCHELL, E.D.; HINTZ, R.L.; WEIBEL, D.E.

Nutritive characteristics of different varieties of sorghum and corn grains. Journal of Animal Science, v.55, n.3, p.665-672, 1982.

IGARASI, M.S.; ARRIGONI, M.D.B.; SOUZA, A.A.; SILVEIRA, A.C.; MARTINS, C.L.; OLIVEIRA,H.N. Desempenho de bovinos jovens alimentados com grão úmido de milho ou com grão úmido de sorgo. Revista Brasileira de Zootecnia, v.37, p.513-519, 2008.

JOBIM, C.C.; NUSSIO, L.G.; REIS, R.A.; SCHMIDT, P. Avanços metodológicos na avaliação da qualidade de forragem conservada.

Revista Brasileira de Zootecnia, v.36, p.101-119, 2007.

LEE, S.Y.; KIM, W.Y.; KO, J.Y.; HA, J.K. Effects of corn processing on in vitro and in situ digestion of corn grain in Holstein steers. Australian Journal of Animal Science, v.15, p.851-858, 2002 
Rev. Bras. Saúde Prod. Anim., Salvador, v.13, n.2, p.516-528 abr./jun., 2012 http://www.rbspa.ufba.br ISSN 15199940

LOPES, A.B.R.C.; BERTO, D.A.; COSTA, C.; MUNIZ, M.H.B.;

PADOVANI, C.R. Silagem de grãos úmidos de milho para suínos na fase final dos 8 aos $30 \mathrm{~kg}$. Boletim da Indústria Animal, v.58, n.2, p.181190, 2001a.

LOPES, A.B.R.C.; BERTO, D.A.; COSTA, C.; MUNIZ, M.H.B.; ROSA, G.J.M. Silagem de grãos úmidos de milho para suínos nas fases de crescimento e terminação. Boletim da Indústria Animal, v.58, n.2, p.191200, 2001b.

MAGALHÃES, P.C.; RODRIGUES, W.A.; DURÃES, F.O.M. Tanino no grão de sorgo: bases fisiológicas e métodos de determinação. Sete Lagoas: EMBRAPA/CNPMS, 1997. 26 p. (Circular Técnica, 27).

MARCONDES, M.I; VALADARES FILHO, S.C.; DETMANN, E.; VALADARES, R.F.D.; SILVA, L.F.C.; FONSECA, M.A. Degradação ruminal e digestibilidade Intestinal da proteína bruta de alimentos para bovinos.

Revista Brasileira de Zootecnia, v.38, n.11, p.2247-2257, 2009

MAKKAR, H.P.S.; BLUMMEL M.; BOROWY, N.K.; BECKER, K.

Gravimetric determination of tannins and their correlation with chemical and protein precipitation methods. Journal Science Food and Agriculture, v.61, p.161-165, 1993.

McSWEENEY, C.S.; PALMER, B.; McNEILL, D.M.; KRAUSE, D.O. Microbial interactions with tannins: nutritional consequences for ruminants. Animal Food Science and Technology, v.91, p.83-93, 2001.
MENDES, A.R.; EZEQUIEL, J.M.B.; GALATI, R.L. Cinética digestiva e eficiência de síntese de proteína microbiana em novilhos alimentados com farelo de girassol e diferentes fontes energéticas. Revista Brasileira de Zootecnia, v.35, n.1, p.264-274, 2006.

MUNIZ, E.N. Adição de metionina protegida da degradabilidade ruminal em rações para cordeiros alimentados com dois níveis de proteína não degradável no rúmen. 2003.98 p. Tese (Doutorado em Zootecnia) - Faculdade de Ciências Agrárias e Veterinárias, Universidade Estadual Paulista, Jaboticabal.

ODENYO, A.A.; BISHOP, R.; ASEFA, G.; JAMNADASS,R.; ODONGO, D.; OSUJI, P. Characterization of tannin tolerance bacterial isolates from East African ruminants. Anaerobe, v.7, p.515, 2001.

OLIVEIRA, M.V.M.; VARGAS JUNIOR, F.M.; SANCHEZ, L.M.B; PARIS,W.; FRIZZO,A.; HAYGERT,I.P.; MONTAGNER ,D.; WEBER,A.; CERDÓTES,L. Degradabilidade ruminal e digestibilidade intestinal de alimentos por intermédio da técnica in situ associada à do sacode náilon móvel.

Revista Brasileira de Zootecnia, v.32, n.6, p.2023-2031, 2003.

OLIVEIRA, R.P.; FURLAN, A.C., MOREIRA, I.; FRAGA, A.L.; BASTOS, A.O. Valor nutritivo e desempenho de leitões alimentados com rações contendo silagem de grãos úmidos de milho.

Revista Brasileira de Zootecnia, v.33, n.1, p.146-156, 2004.

ORSKOV, E.R.; Mc DONALD, L.. The estimation of protein degradability in the rumen from incubation measurements according to rate of passage. Journal Agricultural Science, v.92, p.499-503, 1979. 
Rev. Bras. Saúde Prod. Anim., Salvador, v.13, n.2, p.516-528 abr./jun., 2012 http://www.rbspa.ufba.br ISSN 15199940

PASSINI, R.; BORGATTI, L.M.O; FERREIRA, F.A.; RODRIGUES, P.H.M. Degradabilidade no rúmen bovino de grãos de milho processados de diferentes formas. Pesquisa Agropecuária Brasileira,v.39, n.3, p.271-276, 2004.

PASSINI, R.; SILVEIRA, A.C.; RODRIGUES, P.H.M.; CASTRO, A.L.; TITTO, E.A.L.; ARRIGONI, M.B.; COSTA, C. Digestibilidade de dietas a base de grão úmido de milho ou de sorgo ensilados. Acta Scientiarum, v.24, n.4, p.1147-1154, 2002.

PATRICIO, V.M.I.; FURLAN, A.C.; MOREIRA, I.; MARTINSE, M.; JOBIM, C.C.; COSTA,C. Avaliação nutricional da silagem de grãos úmidos de sorgo de alto ou de baixo conteúdo de tanino para leitões na fase de creche. Revista Brasileira de Zootecnia, v.35, n.4, p.1406-1415, 2006.

PRICE, M.L.; STROMBERG, A.M.; BUTLER, L.G. Tannin content as a function of grain maturity and drying conditions in several varieties of Sorghum bicolor (L.) Moench. Journal Agricultural Food Chemistry, v.27, n.6, p.1270-1274, 1979.

\section{SAS INSTITUTE. SAS language} reference. Version 6. Cary, NC,2001. $1042 \mathrm{p}$.

SARTORI, J.R.; COSTA, C., PEZZATO, L.E.; MARTINS, C.L.; CARRIJO, A.S.; CRUZ, V.C.; PINHEIRO, D.F. Silagem de grãos úmidos de milho na alimentação de frangos de corte. Pesquisa Agropecuária Brasileira, v.37, n.7, p.1009 - 1015, 2002.
SILVA, A.A.; MARQUES, B.M.F.P.P.; HAUSCHILD, L.; GARCIA, G.G.; LOVATTO, P.A. Digestibilidade e balanços metabólicos da silagem de grãos úmidos de milho para suínos. Ciência Rural, v.35, n.4, p.877-882, 2005.

TEIXEIRA, J.C.; HUBER, J.T. , WANDERLEY, R.C. Uso da técnica de saco de náilon móvel para estimar digestibilidade pós-ruminal em vacas leiteiras. Revista Brasileira de Zootecnia, v.18, n.4, p.285-294, 1989.

TONANI, F.L.; RUGGIERI, A.C.; QUEIROZ, A.C.; ANDRADE, P. Degradabilidade ruminal in situ da matéria seca e da fibra em detergente neutro em silagens de híbridos de sorgo colhidos em diferentes épocas. Arquivo Brasileiro de Medicina Veterinária e Zootecnia, v.53, p.100-104, 2001.

VALADARES FILHO, S.C.; MAGALHÃES, K.A.; ROCHA JÚNIOR, V.R.Tabelas brasileiras de composição de alimentos para bovinos. 2.ed. Viçosa, MG: Universidade Federal de Viçosa, 2006. $329 \mathrm{p}$.

VAN SOEST, P.J.; ROBERTSON, J.B.; LEWIS, B.A. Methods for dietary fiber, neutral detergent fibre and nonstarch polyssacharides in relation to animal nutrition. Journal of Dairy Science, v.74, p.3583-3597, 1994

VERVUERT, I.; COENEN, M.; BOTHE, C. Effects of corn processing on the glycaemic and insulinaemic responses in horses. Journal of Animal Physiology and Animal Nutrition, v.88, p.348-355, 2004.

Data de recebimento: 16/08/2011

Data de aprovação: 07/03/2012 